dr. Nives Ličen

Filozofska

fakulteta

$v$ Ljubljani

\section{BIVATI V DRUŽINI - UČITI SE V DRUŽINI}

Družina kot učno okolje
D

ružina in ljubezen sta pojava, ki dokaj trdoživo preživljata vojne, gospodarske krize in različne krize vrednot. Vedno namreč preživita, ker sta zrcalna podoba osnovne človekove potrebe po drugem človeku, pripadanju, druženju in tudi rojevanju novega. Minatti je v svojih verzih zapisal: »Nekoga moraš imeti rad, pa čeprav trave, drevo ali kamen.« Trava, drevo in kamen so uvedeni $\mathrm{z}$ besedno zvezo »pa čeprav«, so nekakšen zasilni izhod. Človek se izpopolni le z drugim človekom, ki mu lahko »nasloni roko na ramo, da se lačna nasiti bližine«. Intimni medsebojni odnosi človeka izpopolnjujejo. V okviru teh odnosov se nenehno uči in osebnostno raste. Namen partnerstva ni le v tem, da sta partnerja zadovoljna, ampak tudi v tem, da drug drugega bogatita.

V zvezi s sintagmo učno okolje pomislimo na šolski razred, predavalnico na fakulteti, mogoče na jezero, kjer se učijo veslati, ali pa na muzej, opero ... Redkeje pa se zgodi, da povežemo učenje $\mathrm{z}$ intimnimi medsebojnimi odnosi. In vendar se prav $\mathrm{v}$ odnosih $\mathrm{z}$ drugimi ljudmi veliko naučimo. V pričujočem prispevku bomo razmišljali o družinskih odnosih kot učnem okolju za odrasle. Vsaka družina je umetnina, ki se nenehno modificira, ki jo partnerja in otroci nenehno ustvarjajo, in je kot taka pomembno učno okolje.

Človek se vedno uči v skupinah, ki jim pripada. Intenzivnost učnih procesov pa je različna. Mogoče je bilo v preteklosti, ko so bile spremembe počasnejše, tako, da so se tokovi spre- memb prelivali $\mathrm{z}$ učenjem in da je človek le plaval s spremembami. Dandanes, v družbi »pospešenih « sprememb, pa je drugače. Ljudje doživljajo korenite spremembe. Pri opazovanju razvoja družine v daljšem časovnem obdobju ali pa v času enega družinskega cikla se zdi, da je to skupina, ki nenehno doživlja modifikacije in mutacije. Nekatere družine v eni generaciji, druge se obdržijo dlje časa.

\section{DRUŽINA V POSTMODERNI DOBI}

Če vzamemo pod drobnogled družino kot obliko zasebnega življenja, vidimo, da se je spremenila na dveh ravneh. Spremenila se je »od znotraj in od zunaj«. Drugo raven obravnavajo sociološki, ekonomski, pravni, statistični, demografski aspekti. Povezani so z no-

Zunanje spremembe, ki se prepletajo z notranjimi spremembani, se povezujejo $z$ dejavniki v družbi in naravi:

- zaposlovanje žensk zunaj doma in širjenje spektra poklicev, ki jih opravljajo ženske;

- podaljšala se je življenjska doba in upadlo je število rojstev, partnerja sta dlje časa skupaj, ne da bi se odločila za otroke;

- družina ni več gospodarska enota z vidika proizvodnje, ampak le $z$ vidika porabe;

- veliko je alternativnih družinskih oblik. 
vimi paradigmami v zvezi z delom, denarjem, zdravjem, šolanjem ...

Izboljšale so se materialne možnosti, tako da mladi pari lahko poskrbijo zase in za svoje otroke. Medsebojni odnosi so se spremenili v skladu s spreminjanjem družine po drugi svetovni vojni: zaposlovanje žensk, upadanje števila porok in rojstev, zviševanje števila ločitev. Vse to kaže na krizo družine kot institucije, ne pa tudi na nezaupanje v skupno življenje. Statistika pravi, da si 75 odstotkov ločenih parov omisli novo partnerstvo (Gelles, 1995). Vse te spremembe se dopolnjujejo tudi z večjim upoštevanjem posameznikovih potreb in njihovim uresničevanjem. Družina deluje včasih kot ovira - kot skupina, ki se ji je treba prilagajati, pri tem pa izgublja posameznik možnosti za samouresničitev. V šestdesetih letih so bile napovedi o prihodnosti družine kot institucije dokaj pesimistične. V socialističnih državah so jo videli kot prenašalko »zastarelih zablod « in potrebno prenove, v zahodnih državah pa je prevladovalo prepričanje, da predvsem utesnjuje posameznika. Vendar štiri desetletja kasneje družina kot institucija še obstaja, le da se je prilagodila in $\mathrm{v}$ svoji plastičnosti odkrila nove oblike skupnega življenja.

Tradicionalni tip razširjene družine je bil v preteklosti pogostejši, ker je bil tak tip družine gospodarska nujnost, saj ljudje niso imeli drugih možnosti. Dandanes raje živijo v tako imenovanih zakonskih ali jedrnih družinah. To velja za starejše in mlajše. Radi živijo v bližini, toda ne skupaj. To, kar sodobniki imenujejo tradicionalni tip družine, se je spremenilo sočasno s poudarjenimi vrednotami. Od kolektivnih so prešle $\mathrm{v}$ individualne, zlasti v dobi moderne, dandanes pa spet kličejo po dopolnjevanju s kolektivnimi vrednotami. Razvoj ni potekal enosmerno, evolucionistično, ne v zvezi z razvojem razširjene družine $\mathrm{v}$ jedrno družino ne $\mathrm{v}$ zvezi $\mathrm{z}$ razvojem kolektivnih vrednot v individualne. Evolucio-

nistične teorije, katerih predstavnik je bil $\mathrm{F}$. Engels, so opredeljevale tradicionalno družino kot homogeno. Obstajala naj bi le razširjena družina ter ena skupina vzorcev vedenja, to je patriarhalni, in en vrednostni sistem kolektivnih vrednot. Raziskave kažejo, da ni bilo tako (Flandrin, 1986; Goody, 1983). Tudi v predindustrijski družbi so obstajale številne oblike in pogosta je bila tudi majhna jedrna družina (Bernardes, 1997). Spremembe zakoreninjenih navad pa so bile počasne, zato so bili tudi procesi učenja transmisijski, znanja, veščine, prepričanja so se prenašali iz generacije $\mathrm{v}$ generacijo. $\mathrm{V}$ postmoderni družini je drugače. Proces učenja je

Postmodernizem se vrača k tradicionalnim vrednotam. hiter oziroma mora biti hiter, kajti zelo hitre so tudi spremembe. Današnja družina je »osvobojena neposredne določenosti s prisilo proizvodnje, zato zagotavlja tisto v zasebnosti potekajočo socializacijo« (Sieder, 1998; 276). Med generacijami naj bi se prenašala najbolj temeljna in prečiščena znanja, stališča, prepričanja.

Kovač (2000), ki govori o postmoderni, meni, da so se razblinile velike utopije in ideologije 19. stoletja in prelomile dobo moderne $v$ postmoderno, ki ponovno išče navdih $v$ kulturnem življenju in v izročilu. Ozira se v preteklost in išče tradicionalne vrednote tudi na področju družinskega življenja.

$\mathrm{V}$ postmodernem iskanju vrednot se je modro izogniti dvema nevarnostma. Prva se kaže v oživljanju raznih fundamentalizmov - religioznih, političnih, rasističnih; druga pa v nevarnosti, da bi zanikali razumskost in bi iskali le v smeri različnih oblik duhovnosti, ki so v nostalgiji po tako imenovani tradicionalni družbi in tudi družini, ki naj bi bila prijetnejša, velikokrat le kvazi duhovnosti. To je iluzija, ki izhaja iz prepričanja o homogenosti družine v predindustrijskem obdobju.

Stare oblike družine in vrednote, povezane $\mathrm{z}$ 
njo, ne morejo več oživeti takšne, kakršne so bile. Tega si sodobni moški in ženske tudi ne želijo. Le kdo bi ponovno uvedel patriarhalni »zakon palca«, s katerim je bilo dovoljeno uporabljati palico, debelo kot palec, za kaznovanje žene in otrok? Imamo pa možnost, da tradicionalne oblike in vrednote kritično premislimo in sprejmemo tiste elemente, ki so primerni današnjemu času, da lahko spodbudijo načine in vzroke, povode za kakovostno oblikovanje življenja. Nevarnost se kaže v tem, da se ob razočaranju, povezanem s pridobitvami sodobnega časa, ki niso v vsem dobre, prostovoljno odpovemo tem pridobitvam in se podamo v regresijo, stran od poguma misli in svobode. To se kaže v vsakdanjem življenju kot želja po prepovedi abortusa, po obsojanju ločitev in govorjenju o »nekvalitetnih otrocih«, ki živijo v enostarševskih družinah, po prisiljevanju ženske, da izbira med vlogo matere in gospodinje ali vlogo zaposlene ženske.

\section{MIKROSOCLALNI SVET DRUŽINE IN UČENJE V DRUŽINSKIH ODNOSIH}

Pojem družina je opredeljen kot bolj ali manj trajna, družbeno priznana zveza dveh posameznikov različnih spolov, ki si ustvarita dom in spočenjata ter vzgajata otroke. Ta oblika obstaja v vseh družbah (Levi-Strauss,

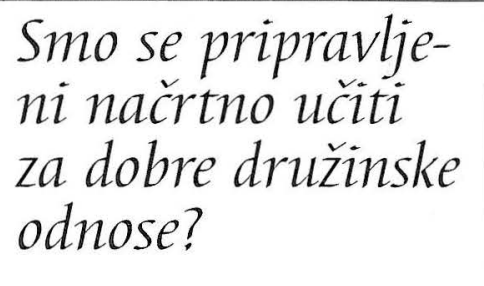

1985; 65). Enotne opredelitve družine ni. V tem prispevku zajema pojem družina partnerja različnega spola $\mathrm{z}$ otroki, ki živijo skupaj. Dve generaciji in dva spola sestavljajo družinski sistem. Temeljna funkcija današnje družine $\mathrm{v}$ zahodni kulturi je reprodukcija. Pogoj za ohranjanje družbe so otroci in ti se večinoma še rojevajo v družinah. Za otroka je družina eksistenčna nujnost, ker sicer ni zmožen niti biološko niti socialno preživeti. Tudi za odra- slega človeka je družina pomembna, včasih prijetna, včasih pa boleča izkušnja. Vsaka družina mora razpasti, da omogoči nastajanje novih družin. Otroci odidejo in si ustvarijo nove družine. Obdobje praznjenja gnezda je za starše neprijetna izkušnja, za otroke pa prijetna, povezana z mnogimi pričakovanji.

Medsebojni odnosi so rdeča nit človekovega učenja v družini. Nekateri so podobni verigi, neprijetni so in težko jih je razkleniti, kot da so večni, drugi pa lahkotni, podobni dobrim mislim ali pa sončnim žarkom v pomladnem jutru. Učimo se iz obojih in od človeka je odvisno, česa se bo iz enih in drugih naučil. Družina kot učno okolje odraslih se $\mathrm{z}$ vidika sistematičnega preučevanja zanemarja.

Pri našem razmišljanju nas zanima mikrosocialni svet družine in učenje posameznika v tej sferi. Ali smo se pripravljeni spreminjati? Ali smo ujetniki navad in stereotipov? Ali se učimo v svojih socialnih vlogah in zanje? Velikokrat ljudje mislijo, da je »dobra družina« nekaj, kar se »zgodi« samo po sebi, da se bodo dobri odnosi razvili sami od sebe. Včasih se to res zgodi, večinoma pa dobre odnose ustvarijo $\mathrm{z}$ načrtnim učenjem in medsebojnim prilagajanjem.

Današnja družina poudarja spontanost in čustvenost, pri tem pa primanjkuje načrtnih spodbud za učenje, bodisi za svet dela ali pa medsebojnih odnosov, medsebojnega komuniciranja. Vsega naj bi se naučili spontano. To pa pomeni, da prenašajo generacije nekatere zelo zastarele vzorce komuniciranja ter tudi nasilnega vedenja in tudi različne mite. Kadar zamenjujemo gospodinjski aparat, ne čakamo, da se bo popolnoma izrabil, ampak kupimo nov aparat, ko se pojavi na trgu in ko ugotovimo, da nam bo olajšal delo. Nadomeščanje je torej načrtno. V medsebojnih odnosih pa smo $\mathrm{v}$ nasprotju $\mathrm{z}$ modernizacijo in udobjem okolja kratkovidni; zastareli vzorci nam ustrezajo, ker ne vidimo možnosti, kako bi se naučili novih. To lahko razložimo tudi z 


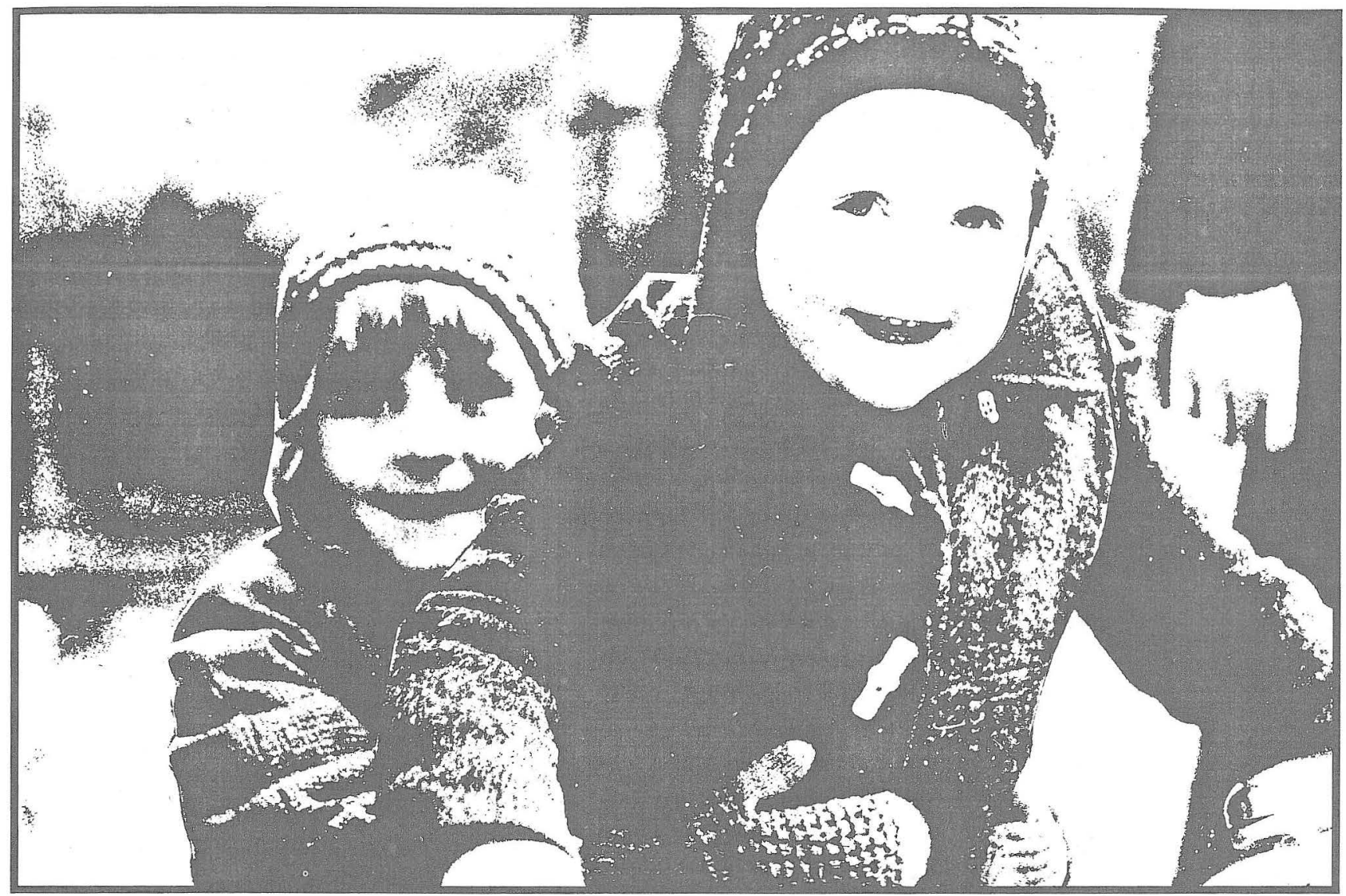

značilnostmi sistemov, ki se vedno upirajo spremembam. Včasih je treba zavestno pospešiti uvajanje sprememb. $V$ petdesetih letih je bilo sramotno, če je oče vozil otroka z vozičkom na sprehod, kasneje se je zdelo zelo pogumno, če je oče sodeloval pri porodu, dandanes pa že večina očetov potiska vozičke $\mathrm{z}$ otroki in veliko jih sodeluje pri porodu. Ravno tako je treba odpraviti nekatere druge predsodke in se naučiti novih, učinkovitejših oblik vedenja $\mathrm{v}$ zvezi $\mathrm{z}$ reševanjem konfliktov, prepirov, dogovarjanjem, o čemer bomo govorili v nadaljevanju.

\section{DRUŽINA KOT SKUPINA, KI REŠUJE PROBLEME}

Družina je konfliktna skupina, ki se uči tako, da rešuje probleme. Problem opredeljujemo kot situacijo, ki vsebuje dosegljive, vendar še ne dosežene cilje. Da bi jih dosegli, je treba premostiti ovire, odpraviti težave. Cilji so želeno stanje, dosežki, ki zahtevajo aktivnosti. Med trenutnim stanjem in želenim stanjem obstaja torej diskrepanca (Scanzoni, 1976).

Potreba po pripadanju in ljubezni je $\mathrm{v}$ svoji skrajnosti v nasprotju s potrebo po svobodi, avtonomnosti in tudi s potrebo po moči ter uveljavljanju samega sebe. Ko sta partnerja zaljubljena, dajeta prednost pripadanju pred svobodo, pri prehajanju v zrelo ljubezen pa se mora to razmerje uravnotežiti, sicer zveza razpade. Če to prehajanje interpretiramo kot minevanje ljubezni, se bosta partnerja dušila v zahtevah po brezkompromisnem zlivanju. To pomeni, da bo prevladoval partner, ki ima večjo moč. Oglejmo si primer iz zakonskega življenja. 
Kaj se dogaja $\vee$ medsebojnih odnosih? Tehtnica med potrebami po avtonomnosti in pripadanju ter moči in varnosti se nenehno ziblje $v$ iskanju ravnotežja. Družina je zato konfliktna skupina, ki mora $v$ odnosih med posamezniki in podsistemi venomer usklajevati povezanost in samostojnost, stabilnost in spreminjanje. Ravnotežja ni. Gre le za njegovo nenehno iskanje, pri čemer dajemo prednost uresničevanju ene potrebe pred drugo.

Andreja in Bojan sta končala študij in se poročila. Na začetku je bilo vse idealno. Počasi sta se med njiju vtihotapili molčečnost, interesi za napredovanje $\mathrm{v}$ službi, zanimanje »zase« je bilo večje kot zanimanje »za naju «. Oba sta bila nezadovoljna, vendar si tega nista želela povedati zaradi lepih spominov na preteklost, da ne bi prizadela drug drugega. Bojan je spoznal v službi vznemirljivo dekle in skupaj sta šla na nekaj službenih potovanj. Andreja je začela zapravljati. Privoščila si je obleke, drago kozmetiko, solarij, masažo ... Sama sebi je govorila, da želi biti privlačna zanj, v resnici pa je utapljala svojo žalost v nepotrebnih nakupih. Ob prenehanju »romantike« zaljubljenosti si nista priznala bolečine. Krivila sta drug drugega. Tako je Andreja venomer govorila: »Najbrž nisem dovolj privlačna, zato ni pozoren do

Potreba po pripadnosti in potreba po avtonomnosti sprožata (konfliktno) družinsko dinamiko. mene, moram si kupiti novo obleko, nove sandale, novo perilo ...« Ali lahko najdeta kak drug izhod iz tega začaranega kroga? Njun zakon je disfunkcionalen, ker nista pripravljena sprejeti sprememb, ki so značilne za vsak odnos, in se učiti iz njih. Zaljubljenost ima svoje zakonitosti, ki pripomorejo k temu, da se odnos začne in ustali. V prejšnjih razmerah je bil odnos trajen, ker je bilo tako določeno s pravili patriarhalne družine ali drugih predpisovalcev norm, na primer cerkve. Dandanes se morata partnerja sama, ne zaradi prisile, ampak zaradi svoje izbire, začeti spraševati o duševnih in duhovnih potezah njunega zakona. Tega učenja v preteklosti ni bilo treba načrtno vključiti v medsebojni odnos, ker sta se zakonca prilagodila družbenim pravilom, ker nista imela možnosti živeti drugače kot skupaj. To pa ne implicira kakovosti zakona. Učenje, ki ga zahteva današnje skupno življenje, ni ne enostavno ne lahko.

Napetosti, ki nastajajo med potrebo po pripadanju in potrebo po avtonomnosti, povzročajo nezadovoljstvo, slabo počutje v družinski skupnosti in tudi interpersonalne ter intrapersonalne konflikte. Z ustrezno interpretacijo dogajanja v družini in odprtostjo za učenje se lahko ustvarijo novi modeli medsebojnih odnosov. Ustvarijo se možnosti za realizacijo družine, ki je adekvatna današnjim razmeram. Učenje je pogoj, da družina ostaja skupaj in dopusti razhajanje, ko se zdi to posamezniku potrebno. Družina je skupnost, katere namen je nastajanje novih družin. Družina nastane, ko se partnerja odločita za skupno življenje in imata otroke, in preneha, ko otroci odidejo, si ustvarijo svoje družine in partnerja ostaneta sama. Zdi se enostavno, vendar v resničnem življenju ni tako, ker prinaša življenje številne težave in trenja, saj ni preprosto »peti in plesati skupaj in veseliti se in hkrati ostati vsak sam kot so same strune na lutnji, pa vendar odzvanjajo isti napev« (Gibran, 1991).

\section{UČENJE IN SOCIALNA MOČ V DRUŽINI}

Do šestdesetih let je bil funkcionalizem prevladujoča teorija o družinski skupini. Zelo redko so se pojavljala vprašanja o moči v družini. Ugotavljali so, da je moč v družini razpršena, da ni osredotočena na enega člana. Avtoriteta, ki se razvije $v$ nizu zavestnih in nezavednih procesov, je učinkovita, kadar jo imamo za legitimno (Burr, 1979). Raziskovanje moči $v$ družini se ni razvilo $v$ okviru funkcionalističnih teorij. Razlago so našli za 
vsako nadvlado. Tako Pitts (1976) ugotavlja, da ima dominantnost moške vloge jasne funkcije, na primer zaščito noseče ženske.

$\mathrm{V}$ petdesetih in šestdesetih letih je bila uporaba besede moč nezaželena. Partnerstvo naj bi bilo enakopravna zveza. Vemo pa, da je moč del vsakega socialnega sistema, vštevši družino. Procese razvoja moči so zanemarili na račun poudarjanja stabilnosti, sporazumov, ljubezni. Trdili so, da je pravica odločanja porazdeljena med vsemi člani družine. $\mathrm{V}$ vsakdanjem življenju je to pomenilo, da so otroci dobili več odgovornosti v zvezi $z$ odločanjem, kot je zmorejo prenesti, in zameglil se je občutek varnosti ob odraslih. V skrajnih primerih so se razvili otroci tirani, ki jih obravnavajo psihoterapevti. Tako so nastala v osemdesetih in devetdesetih letih dela z zgovornimi naslovi, na primer Mali tiran (Prekopp, 1988), Če me imaš rad, mi reci ne (Ukmar, 1997).

Olson in Cromwell (1975, po: Burr, 1979) sta natančneje opredelila tri skupine dejavnikov družinske moči. Prva skupina dejavnikov so viri moči, med katerimi je prvi avtoriteta. Ta temelji na normah. Legitimna moč se povezuje z avtoriteto, nelegitimna moč pa z dominacijo. Naslednji viri so: referenčna moč, izhajajoča iz identifikacije z drugo osebo, ekspertna moč, povezana $\mathrm{z}$ znanjem, veščinami ... neformalna moč, ki se razvija iz sposobnosti prepričevanja drugega, in kaznovalna oziroma nagrajevalna moč, ki izhaja iz možnosti kaznovanja oziroma dajanja nagrad. Druga skupina dejavnikov moči so procesi,

Socialna moč v družini se nanaša na vzorce avtoritete, na slog reševanja konfliktov, na sprejemanje odločitev. Moć je sistem lastnosti, veščin, sposobnosti-potencialnih ali aktualnih -, s katerimi posameznik vpliva na spreminjanje vedenja drugih članov socialnega sistema ali pa na ohranjanje stanja, zadrževanje sprememb. interakcije med člani družine, ki se razvijejo med odločanjem, pogovarjanjem in diskutiranjem, reševanjem problemov, obvladovanjem kriz. Pri tem se kaže asertivnost posameznih članov. Tretja skupina dejavnikov moči v družini pa se nanaša na procese odločanja.

V družini se člani učijo gojiti moč in pripadanje, svobodo in ljubezen, ki jo označujejo odgovornost ter skrb za drugega in tudi asertivnost. Kaj se zgodi, če se ravnotežje poruši in pri posamezniku stopi $\mathrm{v}$ ospredje potreba po moči, lastni uspešnosti, kompetentnosti? Zakonsko življenje ni področje, kjer bi vladala ljubezen brez nasprotij, tako kot otroštvo ni obdobje brez vsake skrbi, čeprav zelo poenostavljeno radi tako razmišljamo. Otroštvo

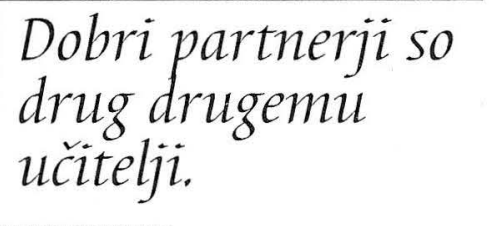
pozna skrbi in partnersko življenje pozna tekmovanje ter odnose moči. Pri nekaterih parih je tekma v moči prikrita, implicitna, včasih je ta tekma taka, da si mož in žena želita podrediti drug drugega $\mathrm{z}$ zapeljevanjem. L'Abate (1994) ugotavlja, da bi se morali za uspešno zakonsko, partnersko življenje učiti ljubezni in pogajanja. Veščine pogajanja je treba obvladati, najprej pa se je treba zavedati, da krize pomenijo možnost za učenje. Partnerstvo je osnovno mesto učenja. Lengrand (1976) meni, da so dobri partnerji drug drugemu učitelji. To misel lahko razvijamo še naprej in ji dodamo, da partnerstvo ne temelji na konkurenci. »Če jaz dobim, mora on izgubiti « je misel, ki ne spodbuja učenja, zlasti ne kooperativnega učenja. Pretirana kompetitivnost ubija medsebojne odnose. Uspeh enega od partnerjev ne more temeljiti na neuspehu drugega. Če temelji družinsko življenje na tekmovanju in izrivanju drug drugega, na zahtevah po posedovanju drugega, lahko pritrdimo Sartrovi misli, da so pekel naši najbližji.

Najbolj znana zgodba o moči iz zakladnice svetovne književnosti je Goethejeva zgodba o Faustu. Goethe jo je pisal vse življenje. V njej pripoveduje zgodbo o moškem, doktorju Fau- 
stu, znanstveniku srednjih let, ki hudiču proda svojo dušo. Želi si biti občudovan, želi si veliko znati, na primer vse svetovne jezike, bogastvo išče v smislu imeti, če uporabimo Frommov izraz. Izobrazba v pogledu imeti je pomembna tudi danes, ljudje si dodajajo nazive kot plemiške naslove. Znanje je pomembno zato, da si izboljšamo življenje, je torej pot in ne cilj, kot je dejal že Grundtvig. Vrnimo se k Faustu. Goethe ga je začel pisati, ko mu je bilo 20 let. Želel je, da bi to delo govorilo o pomembnosti življenja. Nadaljeval ga je pri 40 letih in končal malo pred svojo smrtjo, pri 83 letih. Na začetku želi Faust preizkusiti vse, živeti brez omejitev, brez pogojev, želi govoriti vse jezike, izkusiti vse radosti, prebrati vse knjige ... Hudič mu da vse: zanj ni več človeških omejitev, saj je bogat, politično močan in ženske ga ljubijo. Kljub temu ni srečen. V njem je črna luknja, ki golta užitke. In kaj počne Faust v starosti? Ne zapeljuje več lepih deklet, ampak gradi nasipe, s katerimi ljudje iztrgajo morju nekaj ozemlja in si tako izboljšajo življenje. Moč uporabi za ustvarjalnost v korist drugih ljudi. Torej, najpomembnejša ni moč, marveč pripadanje

Učenje je najučinkovitejse v okoljih, ki so custveno pozitivno obarvana. drugemu.

Če na podlagi zgodbe o Faustu razčlenimo medsebojne odnose v družinski skupnosti, opazimo, da nihajo med izkoriščanjem drugih ljudi za lasten uspeh in izrabo svoje moči za boljše življenje drugih. Ko se na primer mlada ženska vpraša, kakšne koristi ji prinaša prijateljevanje $\mathrm{z}$ moškim, je drugače, kot če se vpraša, kaj lahko skupaj z njim ustvari. Na eni strani so torej v ospredju ambicioznost, bogastvo, imeti, na drugi strani pa je v ospredju biti, ki se kaže v družini kot pripadanje, sodelovanje, popuščanje $\mathrm{v}$ korist skupnih interesov.

Veliko žensk je čustveno osamljenih, ker možje nimajo nikoli časa za skupne cilje. Allan (1999) poroča o raziskavi, ki ugotavlja, da sodobne ženske živijo v čustvenem celibatu, in to je tisto, kar moškemu najbolj zamerijo. Ne zamerijo mu tega, da ponoči vstajajo in nahranijo otroka ..., temveč to, da jim ne stoji ob strani.

Faust je prodal dušo za uspeh, toda ni ga delil z drugimi. Kako živeti, ko imaš vse in nimaš ničesar? Pomagajmo si z mislijo filozofa in teologa Martina Bubra, ki razlikuje dvoje vrst odnosov: Jaz - Ono (bližnji je pri tem objekt, vidimo le dejanja, takih je večina odnosov) in Jaz - Ti (bližnji je pri tem subjekt, presojamo ga kot človeka, pomembni so njegovi motivi in čustva, tako kot so pomembna naša lastna čustva). Zakaj je to pomembno za družinsko učenje? Ker je le malo ljudi, s katerimi ustvarimo odnos Jaz - Ti, družina je ena od tistih skupin, ki to omogoča in ki naj bi se začela s takim odnosom.

Buber opisuje pomemben dogodek v svojem življenju, ki je pripomogel $\mathrm{k}$ razvoju teorije o medsebojnih odnosih. Ko je bil še otrok, so se njegovi starši ločili in odslej je živel pri starih starših na kmetiji. Imel je konja, za katerega je skrbel in ki mu je bil še posebej ljub. Nekoč, ko ga je božal po vratu, je začutil nekaj nenavadnega: njegov odnos do konja je bil takšen, da je začutil, kaj pomeni konju, če ga boža deček. Začutiti, kaj čuti drugo bitje, pomeni preseči meje, ki so med enim in drugim bitjem. To je poseben občutek sreče, ki je silnejši od občutka moči, pri katerem vsiliš svojo voljo drugemu bitju (Kushner, 2000). Ljubezen in moč sta si v skrajnih točkah nasprotni: drugega človeka ljubiš in mu dopuščaš, da je to, kar želi biti, sprašuješ, kaj lahko storiš, da bo čim bolje razvijal svojo individualnost, lahko pa ga držiš v primežu in ga prisiliš, da stori tisto, kar želiš ti. Obojega se učimo in naučeni vzorci se kažejo v partnerskih odnosih in pri vzgoji otrok. Še zlasti za otroke imajo starši pripravljene »zlate načrte«, po katerih naj bi se razvijali.

O starševski vlogi je treba razmišljati, prav tako o partnerskih odnosih in o vlogi moža 


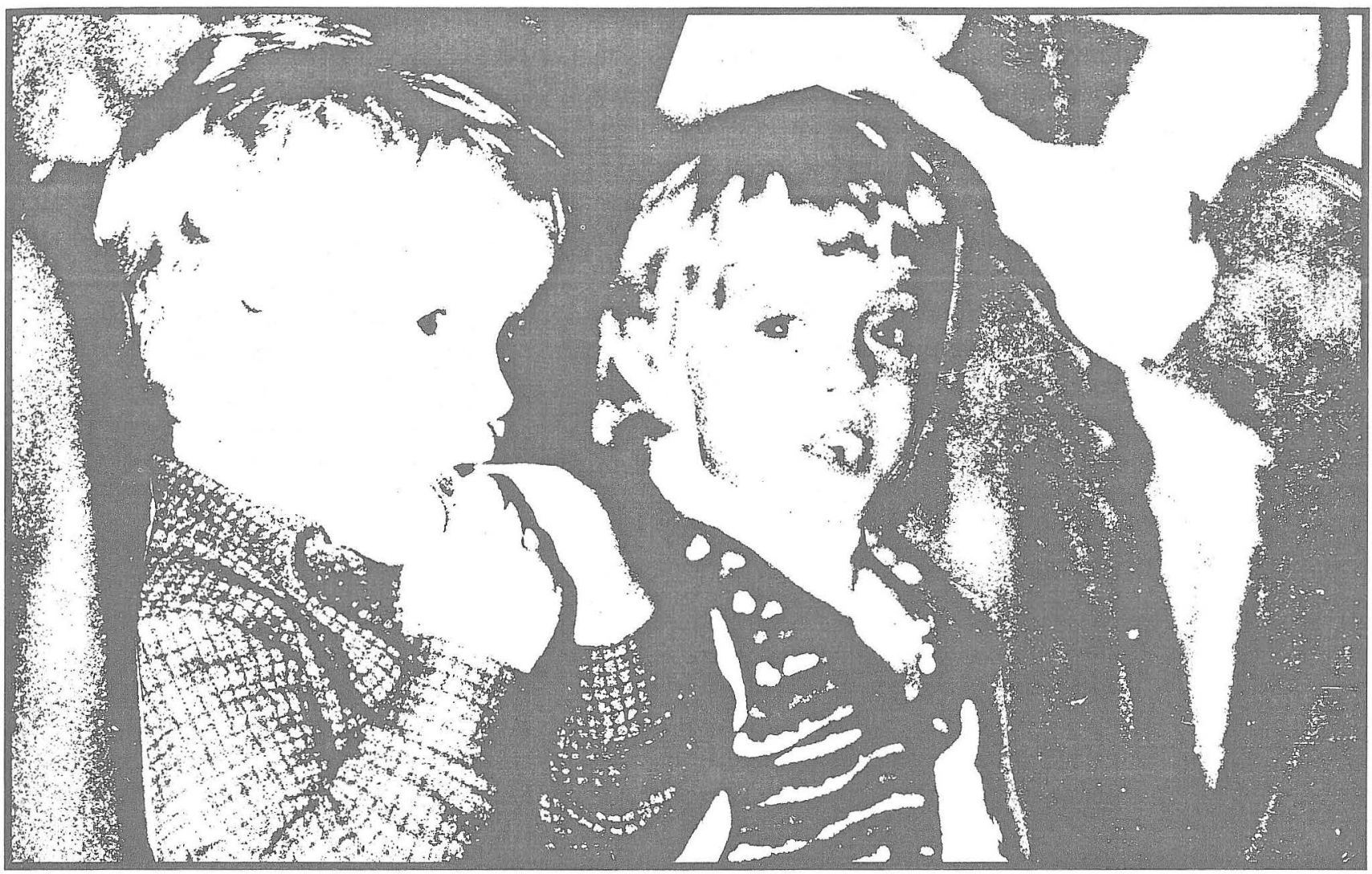

ter žene. Tu gre za izrazito individualno učenje. Andre in Lelord (2000) predlagata nekaj vprašanj, s katerimi ugotavljamo, kaj je vsebina učenja:

- Katere svoje cilje sem uresničil(a) s pomočjo partnerja?

- Zakaj sem ponosn(a) na svojega partnerja?

- Ali sem kaj pripomogel(la) k temu, da je moj partner(ica) dosegel(gla) svoje cilje?

- Je ponosen(na) name?

- Ali izrabljava prednosti partnerskega življenja?

- Ali imava oba »koristi« od skupnega življenja?

- Ali obstajajo področja, kjer tekmujem z njim (njo)?

- Ali obstajajo področja, kjer sva drug na drugega ljubosumna?

- Ali sva se o tem že pogovarjala?
Oglejmo si dva primera in skušajmo ugotoviti, kako bi odgovorili na navedena vprašanja.

Ona je uspešna poslovna ženska, on je učitelj matematike. Ona vedno pravi, da si želi, da bi bil tudi on uspešen, potem bi se ona lahko bolj posvetila otrokoma in družini. Nikoli ne pozabi povedati, da so na srečo njeni dohodki tako visoki, da si lahko ob njegovi »učiteljski mizeriji« privoščijo nekoliko več. Najbližjim prijateljem zaupa, da njemu nikoli ne bo uspelo, da bo vedno le učitelj. Toda, zdi se, da ga ne bi prenašala, če bi mu uspelo. Kajti s tem bi se spremenilo razmerje moči. Mogoče bi jo želel tudi zapustiti. On je priljubljen, nje pa marsikdo ne mara, ker je vzvišena, ker kritizira tudi takrat, ko je nihče ne vpraša za mnenje. Kako sta se uskladila? Njej pripadajo materialne kompetence, ki ji jih on priznava in jo tudi občuduje zaradi sposobnosti. Njemu pripadajo kompetence v zvezi z odnosi, ki 
mu jih ona zavida. Kaj bi se zgodilo, če bi se ravnotežje porušilo?

Brezposelna ženska, ki se izobražuje, se spreminja. Partner ji ne sledi, zato naletita na probleme, ki se v vsakdanjem življenju kažejo tako, da ona kuha in skriva knjigo pod majico, ker njen mož ne želi, da bi še »hodila $v$ šolo«. Če se spreminja le en dejavnik v družinskem sistemu in mu drugi ne morejo slediti (ali je dovolj priseganje na spontanost), vodi to v poslabšanje skupnega življenja, ker mora sistem ostati v ravnotežju.

\section{NORMALNI IN PATOLOŠKI PREPIRI}

V zvezi z močjo v družini nastajajo tudi prepiri. Ti so del vsake družinske dinamike. Družine se ne razlikujejo po tem, ali se prepirajo ali ne, temveč po tem, ali so prepiri »normalni« ali pa patološki. Andre in Lelord (2000) navajata značilnosti enih in drugih.

Cilj normalnega prepira je spremeniti vedenje. Čustva izrazimo neposredno in $\mathrm{v}$ prvi osebi: jezen sem. V takem prepiru iščemo reŠitev: kaj se da storiti? Kritika je usmerjena na dejanja, na primer: ko to in to narediš, mi ustvariš problem. Prepir se konča, ni ne maščevanja ne godrnjanja. Po prepiru se moč uravnoteži, koristi in izgube pa so pri obeh.

Družina - mesto učenja za preseganje lastnega narcisizma.
Cilj nekonstruktivnega prepira je ponižati drugega in pri tem lahko uporabljamo tudi nizke udarce. Odgovornost za svoja čustva se pripiše partnerju, na primer: »Rola se mi zaradi tebe.«, »Ti si kriva.« itd. V prepiru se išče krivec, kajti nekdo mora biti kriv. Kritizira se oseba, na primer: »Ti si res totalka sfalirana in zabluzjena figura.« $»$ A si ti blesav?«

Prepir tli, ne konča se, vedno ga pogrevamo. Je kot žerjavica pod pepelom. Prepir ustvarja neravnotežje, potrjuje dominantnost enega od partnerjev.
Tudi v zvezi z ravnotežjem moči se kaže potreba po izobraževanju. Pasini (1997) ugotavlja, da so se v preteklosti partnerji veliko učili o spolnosti in dandanes se to kaže $\mathrm{v}$ tem, da se sodobni pari laže pogovarjajo o spolnosti in se je učijo kot pa o delitvi moči.

\section{UČENJE ZA SOCLALNO VLOGO KOT UČNI PROJEKTI V DRUŽINI}

Za vsako vlogo se učimo $v$ »spirali učnih projektov«, od enostavnih kompetenc k bolj zapletenim. Tudi prepiranja bi se morali učiti, in to $\mathrm{z}$ jasnim ciljem, da bi opisani nekonstruktivni prepiri prešli v zdrave prepire. Če se partnerja učita le vzorcev prejšnjih generacij, sprejemata tudi vse »spontanosti«, ki v današnjem življenju niso učinkovite. Ko otrok zboli, se pričakuje, da vzame dopust za nego ženska, ker moški ne more ostati doma samo zato, da bi skrbel za otroka. Na oba deluje pritisk okolja. Ženska ostane doma, čeprav bi raje šla v službo in bi moški bolje skrbel za otroka.

Omenili smo, da je za konstruktivno prepiranje potrebno učenje. Še pomembnejše od še tako konstruktivnih prepirov pa je dogovarjanje. Del učenja sodobnih socialnih vlog moškega in ženske je razvijanje sposobnosti dogovarjanja. V navedenem primeru bi se lahko dogovorila, kdo bo ostal doma zaradi bolnega otroka glede na njune preference in ne glede na norme okolja. Primer dogovarjanja se najočitneje kaže v zvezi s številom in časom rojevanja otrok. Scanzoni (1976) je v raziskavi ugotovil, da mlajše izobražene ženske, ki so v svoji vlogi usmerjene v učenje in opuščanje stereotipov, postavljajo kot predmet dogovarjanja čas rojevanja otrok in število otrok, ki jih bosta partnerja imela.

Knowles (1996) govori o izobraževanju v 21. stoletju kot o izobraževanju za različne socialne vloge. Med drugim predstavi tudi socialno vlogo družinskega člana, ki bi se moral za to vlogo učiti oziroma razvijati sposobnosti 
Moč $v$ družini je povezana $z$ vlogami po spolu in normami, ki te vloge opredeljujejo. Socialne vloge so lahko zelo strukturirane, tradicionalne ali pa bolj spontane, manj strukturirane. Tradicionalne vloge po spolu so v druð̌ini doløčene tako, da je ženska podrejena moškemu po nekakšni »hierarhijik, ki ni spontana, ampak družbeno pogojena. Zaradi takšnih navideznih »spontanostik je potrebno načrtno učenje za partnersko življenje, ki večinoma poteka izkustveno, zato potrebujemo znanje o učenju.

za zdravo življenje, načrtovanje, delovanje, pomoč, deliti, učiti se sprejeti, hraniti, varčevati, ljubiti in sprejemati odgovornost. Tega se učijo ljudje sami, spontano, kolikor kdo zmore. Nimamo še izobraževalne ponudbe, ki bi pomagala pri premišljenem uresničevanju partnerske in starševske socialne vloge.

\section{SKLEPNE MISLI}

$\mathrm{V}$ različne oblike sobivanja, $v$ družinsko skupnost nas v sodobnem času ne silijo več razmere, zunanji sovražniki, kot bi lahko imenovali revščino, pomanjkanje, socialno nezaščitenost, zaradi katerih bi bili ogroženi. Družina je dandanes izbira. Osvobojena je nujnosti, zato pa so zanjo značilni večja odgovornost in večja potreba po učenja. Kriza družine, o kateri se je veliko govorilo v šestdesetih letih kot o nepovratni spremembi, se rešuje s premagovanjem normativnih vezi, obveznih oblik in tudi strahov ter mitov iz preteklosti. Ljudje oblikujejo prožna partnerstva, ki so po meri posameznika. Razmišljajo o novih in učinkovitejših oblikah skupnega življenja V družino se ne povezujejo, ker se morajo, ampak ker se hočejo. Gre za izziv, kako ustvarjati iskreno sožitje, določati pravila skupnega življenja in oblikovati socialne vloge. Vse večje je polje tistega, o čemer se lahko pogajajo, vse več je tistega, kar se spreminja, zato se v družini in za družino ljudje intenzivno učijo. Družina ni edina oblika skupnosti, v kateri se učijo o usklajevanju moči in pripadanja ter o preseganju lastnega narcizma. Ker pa je najbolj običajna oblika človeške intimne skupnosti, je najboljše učno okolje za tako učenje.

\section{LITERATURA}

Allan, G. (ed.) (1999). The Sociology of the Family. Oxford: Blackwell Publishers.

Andre, C., Lelord, F. (2000). La stima di se. Milano: Casa editrice Corbaccio.

Bernardes, J. (1997). Family Studies. London, New York: Routledge.

Burr, W. R.; Hill, R.; Nye, I.; Reiss, I. L. (eds.) (1979). Contemporary Theories about the Family. Vol. I., II. New York, London: Free Press, Macmillan Publishers.

Flandrin, J. L. (1986). Družina. Ljubljana: DE.

Gibran, K. (1991). Prerok. Maribor: Župnijski urad sv. Magdalene.

Goethe, J. W. (1975). Faust. Ljubljana: DZS.

Goody, J. (1983). The Development of Marriage and Family. Cambridge: Cambridge University Press.

Kovač, E. (2000). Oddaljena bližina. Ljubljana: Mladinska knjiga.

Knowles, M. (1996). La formazione degli adulti come autobiografia. Milano: Raffaello Cortina Editore.

Kushner, H. (2000). Vivere quando si ha tutto e niente. Vicenza: Neri Pozza.

L'Abate, L. (1994). A Theory of Personality Development. New York: John Wiley \& Sons.

Lengrand, P. (1976). Uvod u permanentno obrazovanje. Beograd: BIGZ.

Levi-Strauss, C. (1985). Oddaljeni pogledi. Ljubljana.

Ličen, N. (2000). Intervjuji s podeželskimi ženskami. Neobjavljeno gradivo.

Minatti, I. (1966). Vse beži z oblaki in s pticami. Ljubljana: DZS.

Pasini, W. (1997). A che cosa serve la copia. Milano: Mondadori.

Planinšek Nanut, Z. (2000). Novi vidiki svetovanja v izobraževanju odraslih. Strokovni posvet Kakovost v izobraževanju odraslih. Portorož, maj 2000.

Prekopp, I. (1987). Der kleine Tyrann. München: KoselVerlag (1998), prevod: Il piccolo tiranno. Milano: Sonzogno.

Ukmar, G. (1997). Se mi vuoi bene, dimmi di no. Milano: Franco Angeli. 